\title{
How to design an education programme for patients with chronic obstructive disease?
}

\section{Learnings from a pilot community pharmacy based project to evaluate patient attitudes}

\author{
MÁTÉ OLÁH, ${ }^{1 *}{ }^{*}$ ATALIN INCZEFFY-IVICSICS, ${ }^{2}$ ÁGNES MÉSZÁROS ${ }^{1}$ \\ ${ }^{1}$ University Pharmacy Department of Pharmacy Administration, Semmelweis University - Budapest, Hungary. \\ ${ }^{2}$ Inczeffy Pharmacy and Medical Centre, Göd, Hungary \\ *Corresponding author: Máté Oláh \\ Email:mate.olah@gmail.com
}

Received: 4 September 2019 / Revised: 3 November 2019 / Accepted: 4 November 2019

\begin{abstract}
Introduction: COPD is a debilitating disease and a major death cause by 2020. Our current knowledge of the opportunities of patient education in the community pharmacy is growing, though yet limited.

Objectives: (1) To assess the potential of a patient education programme in a Hungarian pharmacy in a pilot setting, (2) to understand patient attitudes and gather insight for the development of an education project, (3) to create a sustainable local good practice. Methods: We invited patients with a confirmed COPD diagnosis to take part in an in-depth interview, and to assess their symptoms. Later on, we offered them tailor-made education to learn about their attitudes to create the guidelines for optimal content.

Results: Key elements of the education content should focus on the desire of active life, improve poor adherence, teach about reliever and maintenance therapy and emphasise the chronic component of the disease. Smoking cessation should be fostered, whilst patients would benefit from proper breathing techniques and posture.

Conclusion: Hungarian patients may prefer to get fast and basic education in the community pharmacies. The ideal education content should include pathophysiology, signs and symptoms, treatment options, explanation of medication, inhaler use, smoking cessation and breathing techniques.
\end{abstract}

Keywords: COPD, patient education, ideal content, patient attitudes and perceptions

\section{Introduction}

Chronic obstructive pulmonary disease (COPD) is a respiratory disorder that negatively affects lung function [1], deteriorates quality of life and disables patients to perform their daily duties [2]. It is intercalated by exacerbations, acutely worsening periods, which may require hospital care [1]. The more exacerbations a patient has, the faster their status drops [3].

By 2020, COPD will be the third most common death cause all over the world [4], which poses a severe burden on societies [1]. At the community level, it is our common interest to help patients with this condition, to foster smoking cessation and support their disease management [5]. On top of the effects on the quality of life of the patient, COPD results in a higher rate of utilisation of health services, such as medication, prolonged hospital stay due to exacerbations, as well as the subsequent need of rehabilitation.

Current research trends in COPD disease management indicate that our knowledge of the community pharmacy setting is growing [6, 7], though still not abundant [2, 8]. As of Hungary, we have been unable to identify significant body of research related to COPD patient education in the community pharmacy setting. ${ }^{1}$ Some examples of education in pulmonology centres have been found. These circumstances drive to our attention to an interesting, yet less studied area, for which we have implemented a pilot project in collaboration with the Inczeffy Pharmacy and Medical Centre in Göd.

\section{Objectives}

1. The primary objective was to assess the opportunities of COPD disease management in the community pharmacy in a pilot setting by indepth interviews with current COPD patients who are also future subjects of the education programme.

\footnotetext{
${ }^{1}$ Our Pubmed based advanced search (COPD AND Hungary AND patient education), also checking all relevant articles about (COPD AND Hungary), has not revealed any publication on community pharmacy based education of Hungarian COPD patients (performed by one reviewer, 31 Aug 2019).
} 
Table I Interview methodology guide corresponding to the objectives of the study

\begin{tabular}{|c|c|c|}
\hline Objective & \begin{tabular}{|c|} 
Topic \\
\end{tabular} & Sample questions \\
\hline \multirow[t]{5}{*}{1} & \multirow{5}{*}{$\begin{array}{l}\text { In-depth interviews to understand patient attitudes, } \\
\text { perceptions }\end{array}$} & How do you feel about your disease? \\
\hline & & What disturbs you most in COPD? \\
\hline & & $\begin{array}{l}\text { What would you like to do if you could } \\
\text { breathe freely? }\end{array}$ \\
\hline & & $\begin{array}{l}\text { Do you think your condition will get any } \\
\text { better? }\end{array}$ \\
\hline & & What does a regular day of yours look like? \\
\hline \multirow[t]{5}{*}{2} & \multirow[t]{5}{*}{$\begin{array}{l}\text { Explorative interviews for educational content \& } \\
\text { insights to adherence }\end{array}$} & $\begin{array}{l}\text { Do you have any questions related to your } \\
\text { condition? / What would you like to know } \\
\text { about it? }\end{array}$ \\
\hline & & What have you heard about it? \\
\hline & & Can you tell us how to use these inhalers? \\
\hline & & $\begin{array}{l}\text { What would you like to change about the } \\
\text { condition? }\end{array}$ \\
\hline & & $\begin{array}{l}\text { Do you believe that you / the doctor / your } \\
\text { educator can make a change? How? }\end{array}$ \\
\hline \multirow[t]{2}{*}{3} & \multirow[t]{2}{*}{ Creating local good practice in Göd } & How can the pharmacy staff be engaged? \\
\hline & & $\begin{array}{l}\text { How can we engage local stakeholders to } \\
\text { keep up with the project? }\end{array}$ \\
\hline
\end{tabular}

2. The secondary objective was to understand patient attitudes, perceptions, fears, beliefs that affect the everyday life of patients. This is highly valuable input to the education programme, because it sets the guidelines for the educational content, whilst providing major insights into how patients relate to their disease.

3. The tertiary objective was to create a local good practice and to investigate how the community pharmacy pillar of integrated care can work in the context of a small town in Hungary.

\section{Methods}

\subsection{Study context}

Göd is a medium-size city with around 19,800 inhabitants [9]. According to the Rotterdam Study [5], COPD prevalence on an overall basis is $4.6 \%$, so $5 \%$ seems to be a rationale approximation in a European setting [4]. This means that the overall COPD population of Göd should be around 95 people, out of which, $\mathrm{N}=6$ were included in our study (7\%). Inczeffy Pharmacy is a central and well-known community pharmacy in the city, and it has gained an innovative reputation due to their previous commitment in previous patient education programmes.

This explorative study joins methodologically a series of studies. Besides patient interviews in the pharmacy and the pulmonology outpatient centres, pulmonologist expert opinion was assessed to develop an education programme for the COPD patients. Later on $\mathrm{n}=118$ patients were provided education, and their quality of life and adherence changes were monitored in a longitudinal study with follow-up. The in-depth interview methodology, applied in this context, helped us explore the opportunities of patient education in the pharma$\mathrm{cy}$, and also to lay more stress on the pulmonology centre pillar.

\subsection{Inclusion of study participants}

During dispensing medication, patients with the J44 ICD classification code were offered to participate in the pilot project. Altogether, patients were screened for 5 working days, 25 showed their interest, and 8 were willing to participate in the education session, and finally 6 patients showed up.

\subsection{Interview methodology}

We have performed exploratory in-depth interviews with the patients [10]. The structure of the interview has been designed to determine the key elements of a patient education programme; and to let them discover perception and therapeutic attitudes [11]. Table I provides an overview of this structure and an insight into the explorative questions. One interview lasted ca. 30 minutes. The methodology showed some mixed features with a loose semi-structured interview, since we primarily set the major topics we wanted to direct pa- 
tients to. Altogether, interviewed them by using the active listening technique, which means that we concentrated on their thoughts and let them relatively freely talk about their condition. At the end of the interviews, patients participated in an educational session (prototype education) where they could ask freely about their doubts related to their disease. Their reactions were assessed before and after the prototype session.

\subsection{Symptom assessment}

We invited the patients to self-administer the COPD Assessment Tool (CAT), ${ }^{2}$ which is a standard method to assess symptomatology in pulmonology practice [12]. CAT is an 8-item questionnaire to assess their symptoms on an ascending scale until 5, and scores range 0-40. Patients are considered symptomatic above 10 scores.

\section{Results}

The community pharmacy setting is a challenging venue for patient education. Originally, we intended to incorporate a comparative aspect to a longitudinal study which assesses the impact of education on quality of life and adherence; however, pharmacy patients turned out to be more willing to be educated in a one-time occasion than in a follow-up intervention. Consequently, the community pharmacy pillar to this study was halted, whilst the interviews provided patient insight to the education content we developed for the further course of the aforementioned study. The patients' desire to get pharmacist advice fast [2], seems to also appear in a German setting, which verifies the need for pharmacy disease management projects (patients who attended such sessions were enabled to use their inhaler significantly better, although this means $29 \%$ overall) [13]. This idea has been further developed in Japan, where pharmacist-led clinics were proven to improve quality of life [14].

\subsection{In-depth interviews to understand patient attitudes, perceptions}

Patients did not mention the textbook like symptoms (sputum secretion, dyspnoea and coughing) on the first instance; however, they always relate to real-life actions they would like to perform: to

\footnotetext{
${ }^{2}$ We fully complied with the guidelines at https://www.catestonline.org, and we solely used the licence for academic research purposes.
}

play tennis, to play with the grandchildren and to paint. Falsely, they identify their illness as asthma, and they see no relation to smoking (but one patient). They get used to the symptoms, and they mostly perceive them as "they come by age", "they are natural"; thus, they accept their conditions. These activities should be used when developing the patient profile for the education content; additionally, we should use the patients' own words to help them memorise its content. Figure 1 summarises the results for the education content.

\subsection{Educational content and insight to adherence}

None of the patients was able to identify the reliever drug; even the most asymptomatic patient used it every morning, in an inadequate dose. Once-daily inhalers were preferred, since one occasion is the frequency everyone declared as adequate for the treatment of the disease. One patient reported a willingness to apply alternative methods, namely she was interested in herbal drinks as a possible treatment option. The patients were unaware of the inhalation therapy they used; hence, there was no apparent fear of steroids. Based on their CAT scores, all patients were symptomatic, which implies that they are either not compliant, or do not have the right medication.

The interviews reveal a truly diverse image of COPD attitudes. The main symptoms are feeling powerless and the lack of physical performance. Two patients mentioned repeatedly their disability in moving and taking the stairs, and one patient was completely confined to oxygen therapy.

The lack of adherence is a variant which was challenging to get the patient talk about. Finally, they all confessed that they either do not take their medication in the prescribed manner, or make changes to treatment regimens upon self-judgement. The better they feel, the less they take the medication.

\subsection{A local good practice}

Since the project was well-accepted, a local epitome has been created in the Inczeffy Pharmacy. It is our ambition to keep this project going, and in order to maximize the impact our our research, interested pharmacies are invited to collaborate throughout Hungary.

Our results are in line with review articles in COPD patient education in the community pharmacy setting $[15,16]$. The primary roles of the pharmacist should be to assess the current symp- 


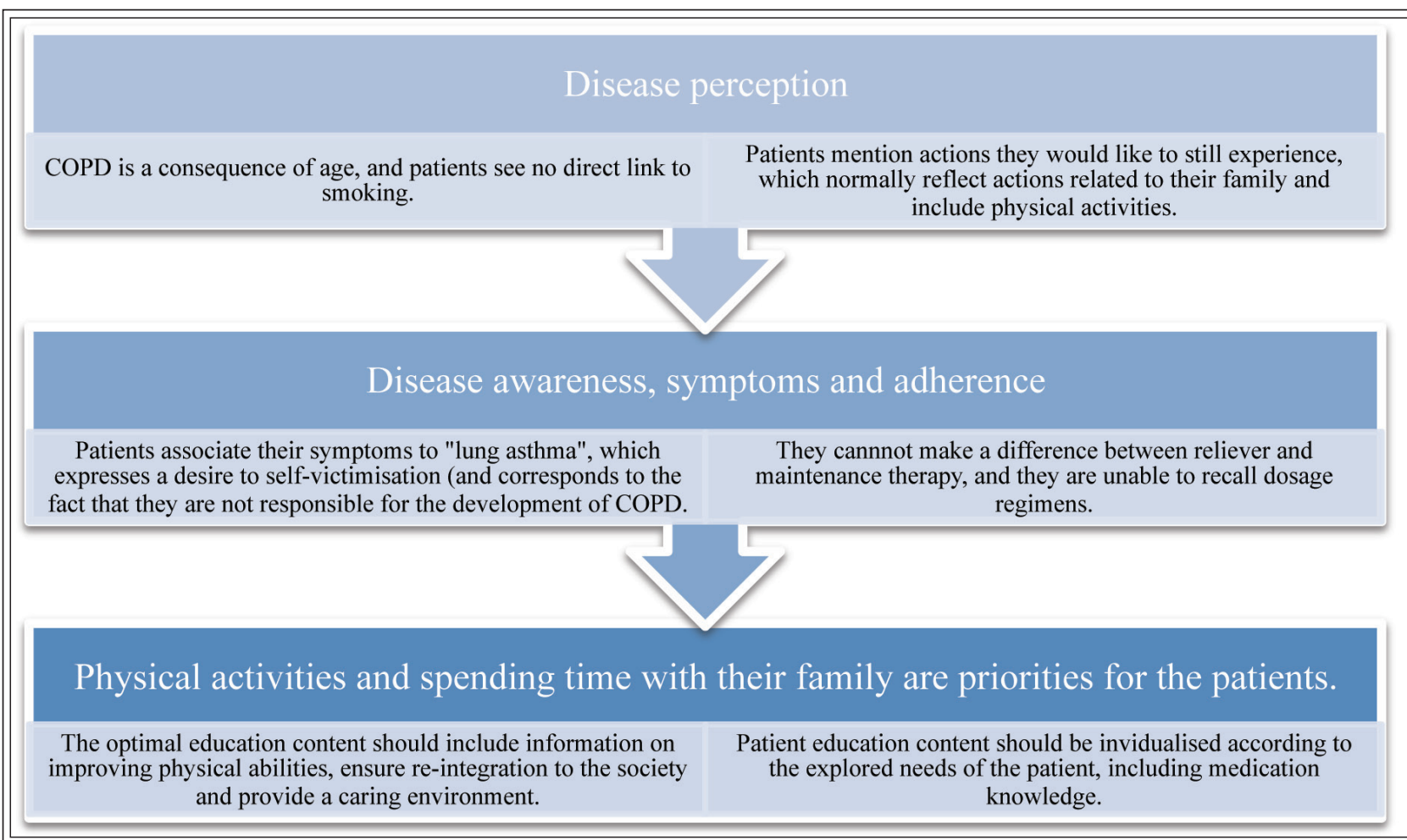

Figure 1 Major patient perceptions $\mathcal{E}$ attitudes and their implications for the development of education content

toms and improving smoking habits, inhaler technique, dosage and medication use, and the provision of materials to support these activities. Based on the input provided by this study, we can state that the education materials created reflect international good practice.

\section{Discussion}

While designing the education content, I identified similar body of research which describes an educational project with $n=62$ patients with moderate to mild COPD ( $<70$ years of age), who participated $2 \times 2$ hour weekly session, with 1 week gap fashion [17]. Education was performed through a 19-page booklet with information on self-assessment and disease management. Oral sessions included education on the respiratory obstruction, anti-obstructive medication, exacerbation prevention, self-assessment and self-management, and physiotherapy. This is a definite similarity with our research, since the major elements of the education are overlapping. In line with our results, the implication of this is that we should make sure that patients understand that COPD is a chronic condition, and medications should be taken; also in case they feel right. Interestingly, SMART dosage is available in the case of certain drugs, so this is another aspect that should be included in the education content.

Asking the patient and the caregiver at the same time can draw our attention to new discoveries [18]. For the conceptual perception assessment, it is worth including patient and caregiver interviews to map the needs of the most important stakeholders of COPD care in Hungary. This current study evaluated the importance of pharmacist care and the educational opportunities in the community pharmacy setting. It is important to note that patients originally did not associate lung problems with the pharmacists' relevant knowledge, though confidence was built up once they realized that their doubts were correctly addressed.

In order to keep up with this spirit and to build the educators' reputation in the project, we identified the following key benefits of employing a pharmacist in the project, along with [19]:

1. primary prevention: campaigns, lifestyle counseling, awareness raising;

2. early diagnosis;

3. management and ongoing support: pharmacist care, information on inhalation device use, disease outlook, dosage, self-management of the disease;

4. overview and follow-up: monitoring adherence 
and device use. This connects to the content of the community pharmacy pillar of our education, and we considered these points to define the potential role of the pharmacist in our education project.

An important methodological point is highlighted: due to the heterogeneity of the studies, it is very hard to set up the optimal education, based on the publications reviewed, but it may be tailormade [20]. Finding the right balance between fixed content to keep measurements intercomparable is a methodological prerequisite, whilst personalization seems to bring the most benefits to the patient.

Taking the matter of standardization of education content to a national level, data providers in Germany present such diversity that prefer not to compare [21]. The study confirms that these education projects should be either aligned individually or require a higher level of coordination for initiation. The most common errors that were found in 46 of the 95 programs are as follows: evaluation of program success, inadequate transparency of cost data and the lack of the same in quality of life interventions. It seems clear that success rates should be defined, although there are no consensus or an established method [22]. A prerequisite for the achievement of success indicators is that the patient is actively involved in the therapeutic process and has an individual action plan for the self-management of the disease [23]. Although very softly, $[24,25]$ also affirm that a caring environment, nice and competent words initiate the self-management process in the COPD patient. That is why we considered it supremely important along this study to keep patients motivated, especially by providing answers to all additional questions, once the sessions were over, and the education with fixed content was delivered.

A holistic summary of patient education opportunities [26] include printed brochures, recorded videos and audio-visual materials, self-education, self-monitoring, self-directed therapy, patient involvement in therapy, patient interviews on side effects, organization of self-help and therapy groups, telemedicine, computer and internet patient information, targeted interventions to improve health literacy in disadvantaged groups, and targeted media campaigns. The methods mentioned here depict another process: media and telemedicine should be the future direction, though currently we have not identified this need from our patients, apparently it would have been a disadvantage at this phase. Currently, we applied the methods in italics, and focused on the major benefit of the education sessions highlighted by the interview subjects, which is, personal care and assistance throughout the project.

A Canadian patient education project [27] covered adherence, inhalation techniques, health-related quality of life, and the use of health resources such as drug therapy and COPD exacerbations. Content included explanation of the current therapy, dosage, administration, patient expectations, duration of therapy, and potential outcomes, and follow-ups and improved inhaler use. By the "teach it back" strategy, understanding the components of adherence caused by a lack of knowledge and the patient's perceptions of the disease have helped to enhance adherence. The "teach it back" strategy that is also vastly recommended by our interviews, patients appreciated when their opinion was considered and they were included in the sessions by embracing their true self and attitudes.

An analog of this study [28] examined COPD self-management on $\mathrm{n}=176$ patients, with the following education content: COPD status, medication, and respiratory training. Education should be structured to ensure that the measurements are inter-comparable. The education should consider the patients' capabilities, so that the content can be acquired, and it has cost-effective long-term effects: less frequent exacerbations result in decreased use of healthcare resources [29].

The Belgian PHARMACOP study [30] shares the methodology of [31] and they are very similar to the final study design of our investigations. Altogether, $\mathrm{n}=734$ patients were enrolled and followed for 3 months. Adherence to maintenance therapy and the use of inhalation devices were the focus of the study, and education was provided to patients at baseline and after 1 month. Both variables were significantly better in the intervention group, and a significantly lower number of hospitalizations were reported. Using the in-depth interview method, $n=173$ patients were reported that the absence of depression, comorbidities, and patient perception of the disease have a much greater impact on adherence than demographics or disease severity [28].

A major limitation for the first sight is the numbers of patients included in the study. In the setting of Göd, this means 7\% inclusion of the whole population. In order to achieve the same power of significance, we would need to include 35,000 pa- 


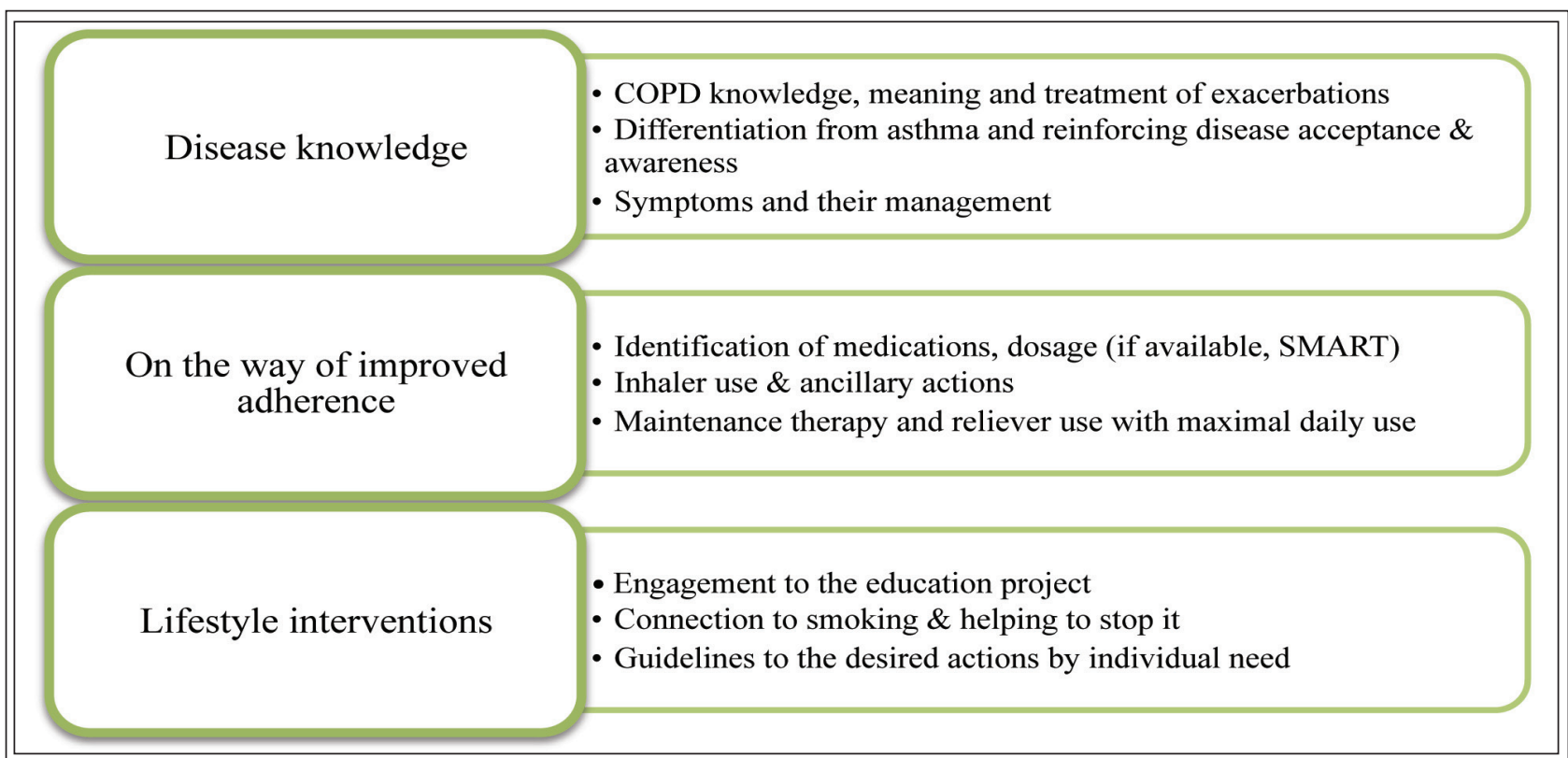

Figure 2 Elements of the suggested education content by COPD patients

tients for Hungary, considering 500,000 COPD patients in the country [5]. Consequently, this aspect is considered as a relative limitation; however, it is an obstacle of the general applicability of our conclusions.

\section{Conclusions and caveats}

We have developed an education content for COPD patients based on the input from patients from the community pharmacy. The education programme should reinforce physical activities, tailor-made to the current condition of the patient; furthermore, breathing techniques should be incorporated to avoid the abrupt appearance of breathlessness. Our relatively small sample demonstrated such a diversity (like the ladies' interest in alternative methods) that corresponds with patient beliefs described in the literature.

Patient interviews vastly reveal the missing concepts, lack of pragmatic knowledge and (non)adherence data that should be tackled by in our education programme. A patient education project was piloted in the community setting, and we will do our best to ensure the scientific support to its continuation (hopefully this means that research objective III will continue on the long-term in Göd). Furthermore, this study has the benefit to envision the three key intervention areas that should be targeted by an education programme.

1. A relatively small number of COPD patients prefers the pharmacy to get education; however, those who come indeed, are motivated. Pa- tients get used to COPD, and they accept "that this comes by age", "I cannot do this", though all of them mentioned an activity they still wish to pursue.

2. Active listening to patient needs is an effective way to reveal important insight [11]. Namely, asking semi-structured questions; and permitting them to talk about their issues helped us create the guidelines for such content they can benefit. Recording patients' words and phrases also helps us to put together an easy-to-understand material with catchy content. There is a need to expand the project, since once the patients decided to open up, they share all their experience; furthermore, these patient clubs are also in favour of their social inclusion and provide an opportunity to meet their peers.

3. Research objectives I and II have been also met, and our findings are summarised in Figure 2. This table also seeks to incorporate the patient insight to an ideal education content. Since the project was well accepted, a local epitome has been created in the Inczeffy Pharmacy.

4. It should be noted that the generalizability of our results is limited due to the small amount of patients included in the study, though this number represents $7 \%$ of the total COPD population of Göd. Consequently, our results can be primarily applied in similar setting of towns or smaller cities.

5. These results imply for the further development of research, that COPD patients prefer to take part in education more in the pulmonology out- 
patient centre setting than the pharmacy. In order to meet this need, a larger number of patients were recruited from the latter setting.

\section{Acknowledgement}

The authors are grateful to the team of the Inczeffy Pharmacy.

\section{Competing interests}

The authors declare no conflict of interest, monetary or otherwise.

\section{References}

1. Hattab, Y., Alhassan, S., Balaan, M., Lega, M., Singh, A.: Crit. Care Nurs. Q. 2016; 39: 124-130. https://doi. org/10.1097/CNQ.0000000000000105

2. Bollmeier, S., Seaton, T., Prosser, T. R.: Journal of the American Pharmacists Association 2019; 59, 479-488. no. https://doi.org/10.1016/j.japh.2019.04.017

3. Spencer, S., Calverley P., Burge, P., Jones P.: European Respiratory Journal 23, 2004; 698-702. https://doi. org/10.1183/09031936.04.00121404

4. Raherison, C., Girodet, P. O.: European Respiratory Review. 2009; 18, 213-221. https://doi. org/10.1183/09059180.00003609

5. Terzikhan, N., Verhamme, K. M., Hofman, A., Stricker, B. H., Brusselle, G. G., Lahousse. L.: Eur J Epidemiol. 2016; 31, 785-792. https://doi.org/10.1007/ s10654-016-0132-z

6. Hesso, I., Gebara, S., Kayyali, R.: Respiratory Medicine 2016; 118, 22-30. https://doi.org/10.1016/j. rmed.2016.07.010

7. Hohmeier, K., Masselink, A.: J App Pharm 8, 214. (2016). https://doi.org/10.4172/1920-4159.1000214

8. Fathima, M., Saini, F. F. B., Armour, C.: International Journal of COPD 2017; 12, 2753-2761. https://doi. org/10.2147/COPD.S145073

9. KSH: "Magyarország közigazgatási helynévkönyve". http://www.ksh.hu/docs/hun/hnk/ hnk_2019.pdf [accessed: 3/11/2019]

10. Rosenthal, M.: Currents in Pharmacy Teaching and Learning 2016; 8, 509-516. https://doi.org/10.1016/j. cptl.2016.03.021

11. Bovea, D., Midtgaard, J., Kaldana, G., Overgaard D., Lomborgef, K.: Journal of Psychosomatic Research 2017; 98, 71-77. https://doi.org/10.1016/j.jpsychores.2017.05.013.

12. Gupta, N., Pinto, L., Morogan, A., Bourbeau, J.: European Respiratory Journal 2014; 44: 873-884, no. https://doi.org/10.1183/09031936.00025214

13. Axtell,S.,HainesS.,Fairclough,J.:JPharmPract.30,195201. (2017). https://doi.org/10.1177/0897190016628961

14. Yamada, K., Nabeshima, T.: J Pharm Health Care Sci. 2015; 1, 2. https://doi.org/10.1186/s40780-0140001-4
15. wigg, M. J. Wright, D. J.: Integr Pharm Res Pract. 6, 53-59. (2017). https://doi.org/10.2147/IPRP.S105279

16. Barefield, K. L., DeBellis, H. F.: J Am Coll Clin Pharm. 2019; 2, 433-443. https://doi.org/10.1002/jac5.1151

17. Gallefos, F.: Patient Educ and Couns. 2004; 52, 25966. https://doi.org/10.1016/S0738-3991(03)00100-9

18. Guo S. E., Bruce A.: PLoS One. 9: e110835. DOI: 10.1371/journal.pone.0110835 https://doi.org/10.1371/ journal.pone.0110835

19. van der Molen, T., van Boven, J. F., Maguire, T., Goyal, P., Altman, P., Br J Clin Pharmacol. 2017; 83, 192201. https://doi.org/10.1111/bcp.13087

20. Bourbeau, J., Lavoie, K. L., Sedeno, M.: Semin Respir Crit Care Med. 2015; 36, 630-638. https://doi. org/10.1055/s-0035-1556059

21. Küver, C., Beyer, M., Gensichen, J., Ludt, S., Schmitz, A., Szecsenyi, J., Gerlach, F. M.: Z Arztl Fortbild Qualitatssich. 2004; 98, 393-402.

22. Clari, M., Matarese, M., Alvaro, R., Piredda, M., De Marinis, M. G.: Heart Lung 2016; 45, 441-8. https:// doi.org/10.1016/j.hrtlng.2016.06.006

23. Reddel, H. K., Jenkins, C. R., Partridge, M. R.: Int J Tuberc Lung Dis. 2014; 18, 1396-406. https://doi. org/10.5588/ijtld.14.0371

24. An, M. H., Choi, J. Y.: Korean Journal of Adult Nursing 2012; 24, 2. https://doi.org/10.7475/kjan.2012.24.2.160

25. Chang, Y. Y., Dai, Y. T., Chien, N. H., Chan, H. Y.: J Nurs Scholarsh. 48: 466-71. https://doi.org/10.1111/ jnu.12230

26. Neri M.: Monaldi Arch Chest Dis. 2008; 69, 47-49. https://doi.org/10.4081/monaldi.2008.394

27. Davis, E., Marra, C., Gamble, J. M., Farrell, J., Lockyer, J., Fitzgerald, J. M., Abu-Ashour. W., Gillis, C., Hawboldt, J.: Trials. 2016; 17, 502. https://doi.org/10.1186/ s13063-016-1623-7

28. Khdour, M, R,, Kidney, J. C., Smyth, B. M., McElnay, J. C.: Br J Clin Pharmacol. 2009; 68, 588-98. https://doi. org/10.1111/j.1365-2125.2009.03493.x

29. Sari, N., Osman, M.: BMC Health Serv Res. 2015; 15, 332. https://doi.org/10.1186/s12913-015-0998-6

30. Tommelein, E., Mehuys, E., Van Hees, T., Adriaens, E., Van Bortel, L., Christiaens, T., Van Tongelen, I., Remon, J. P., Boussery, K., Brusselle, G.: Br J Clin Pharmacol. 77, 756-66. https://doi.org/10.1111/bcp.12242

31. Hämmerlein A, Müller U, Schulz M.: J Eval Clin Pract. 2011; 17, 61-70. https://doi.org/10.1111/j.13652753.2010.01369.x

32. Effing, T., Monninkhof, E. M., van der Valk, P. D., van der Palen, J., van Herwaarden, C. L., Partidge, M. R., Walters, E. H., Zielhuis, G. A.: Cochrane Database Syst Rev. 4, CD002990. https://doi.org/10.1002/14651858. CD002990.pub2

33. Miravitlles, M., Ferrer, J., Baró, E., Lleonart, M., Galera, J.: Respir Med. 2013; 107, 1977-85. https://doi. org/10.1016/j.rmed.2013.06.019

34. Brien, S.B., Lewith, G.T., Thomas, M.: NPJ Prim Care Respir Med. 2016; 26, 16051. https://doi.org/10.1038/ npjpcrm.2016.51

35. Trivedi, R.B., Bryson, C.L., Udris, E., Au, D. H.: Ann Behav Med. 2012; 44, 66-72. https://doi.org/10.1007/ s12160-012-9355-8 
